\title{
Health Economics and Health Policy: Experiences from New Zealand
}

\author{
Jacqueline Cumming
}

Published online: 13 January 2015

(c) Springer International Publishing Switzerland 2015

\begin{abstract}
Health economics has had a significant impact on the New Zealand health system over the past 30 years. In this paper, I set out a framework for thinking about health economics, give some historical background to New Zealand and the New Zealand health system, and discuss examples of how health economics has influenced thinking about the organisation of the health sector and priority setting. I conclude the paper with overall observations about the role of health economics in health policy in New Zealand, also identifying where health economics has not made the contribution it could and where further influence might be beneficial.
\end{abstract}

\section{Key Points for Decision Makers}

Health economics has had a significant impact on the New Zealand health system over the past 30 years.

This is particularly the case in relation to the organisation of the health sector and some aspects of priority setting (principally, in relation to medicines and waiting times).

Health economics has been less successfully applied in terms of priority setting more generally, and there remain some key gaps, where further health economics analysis is needed to further improve the performance of the New Zealand health system.

J. Cumming $(\bowtie)$

Health Services Research Centre, School of Government,

Victoria University of Wellington, P O Box 600,

Wellington 6140, New Zealand

e-mail: jackie.cumming@vuw.ac.nz

\section{Introduction}

In this paper, I argue that health economics has had a significant impact on the New Zealand health system over the past 30 years, but that there are still key areas where further health economics analysis is needed to further improve the performance of the New Zealand health system. The paper is divided into five sections. First, in this introduction, I set out a framework to guide the discussion. Second, I provide some historical background about New Zealand and the New Zealand health system. Third, I discuss how health economics has influenced thinking about the organisation of the health sector. Fourth, I examine the role of health economics in priority setting in New Zealand. In the fifth and final section, I conclude the paper with overall observations about the role of health economics in health policy in New Zealand, also identifying where health economics has not made the contribution it could and where further influence might be beneficial.

Economics is defined as 'the study of how scarce resources are or should be allocated', with microeconomics examining 'how production and consumption are organised, what is produced, and who benefits' [1] p. 137. Williams [2] discussed health economics in terms of eight key areas of focus (see Fig. 1):

A. What influences health (other than health care)?

B. What is health and what is its value?

C. The demand for health care

D. The supply of health care

E. Micro-economic evaluation at treatment level

F. Market equilibrium

G. Evaluation at whole system level

H. Planning, budgeting and monitoring mechanisms. 


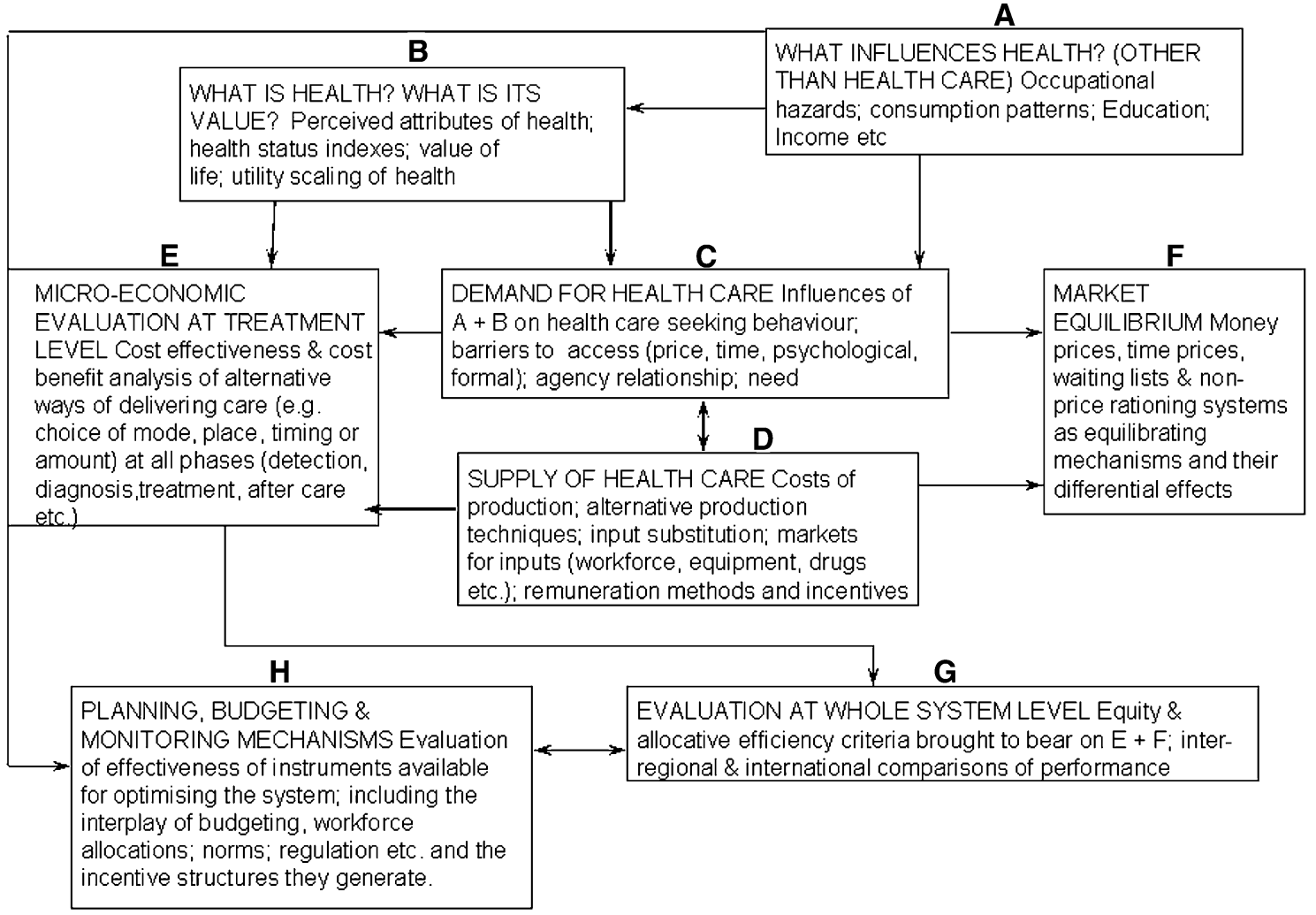

Fig. 1 Scope of health economics. Source: [2]

This framework is used in this paper to discuss the role of health economics within the New Zealand health system.

\section{Background to New Zealand and the New Zealand Health System}

New Zealand is a small, island nation, located in the south western Pacific Ocean. Its original indigenous inhabitants are Māori. In 2014, New Zealand has an estimated population of $4,547,000$ [3]. The population is predominantly of European ethnicity (74\%), and there are significant Māori (15\%), Pacific Island (7 \%) and Asian (12\%) populations [4].

The New Zealand health system has been predominantly government funded since the early 1940s, and public funding currently accounts for $83 \%$ of total health expenditure [5]. Government-owned hospitals provide accident and emergency, inpatient, outpatient, and community care free of charge to all New Zealanders. Primary health care services such as general practitioner (GP), pharmacy, and diagnostic services have traditionally been delivered through privately owned, small independent businesses, funded by government fee-for-service subsidies, with service users also paying fees for GP services (maternity care is free, as are GP services for those under 6 years of age; from mid-2015, free GP care will extend to those aged under 13 years). Pharmaceuticals are also subsidised by government, free of charge for patients until the mid-1980s; there is now a \$NZ5 per item user charge for many service users.

Accident-related care is funded through a governmentowned separate insurance agency [known as the Accident Compensation Corporation (ACC)]. New Zealanders can also purchase private health insurance- to get faster access to elective services, cover user charges, and access better facilities (e.g., single hospital rooms). All privately funded hospital care is delivered in privately owned hospitals.

The New Zealand health system is seen as performing reasonably well, given that it provides universal coverage, high levels of access to a comprehensive range of services, high quality care, overall high levels of health status, and generally good value for money [6]. Key, on-going concerns about the New Zealand health system, however, include:

(a) The demand for health care, arising from barriers to accessing primary health care services, including financial barriers arising from high user charges

(b) The supply of health care, including concerns over: having many small local hospitals, resulting in inefficiencies and poor clinical quality of care; fragmented care arising from the wide range of providers involved in delivering care; insufficiently 
comprehensive primary health care delivered largely by GPs only; and poor incentives to deliver responsive care

(c) Market equilibrium, in particular surrounding long waiting times for elective services and non-price rationing (in this paper, referred to as priority setting) systems

(d) Evaluation at whole system level, including concerns over lower levels of health for Māori, Pacific, and lower income New Zealanders and the overall organisation of the health system

(e) Planning and budgeting, arising from poor-and politicised-decision making, resulting in cost-ineffectiveness and inefficiencies in service delivery [7-14].

This paper examines (c) and (d) in particular; examining evaluations at the whole health system level [issue (d) above] first, before moving on to examine issues relating to market equilibrium. Readers are referred to Cumming et al. [6] on how other key issues have been approached in recent years.

\section{New Zealand Health Economics and Evaluations at the Whole Health System Level}

Given the significant role that the New Zealand government plays in financing and delivering health care, the importance of health services to New Zealanders and hence to government, and the focus of governments on restructuring health systems as a key means available to them to improve health system performance, it is no surprise that many attempts have been made to re-organise New Zealand's health system over many years. In this section of the paper, I examine the various attempts at re-organisation, and in particular, the role of health economics thinking in health system reviews and re-organisations. The focus is particularly on reviews and reforms since the 1980s.

\subsection{Re-Organising the Health System-to 1990}

Numerous attempts were made from the 1940s to the 1970 s to reform New Zealand's health system, to deal with the key concerns noted above. The only main changes to be achieved prior to the 1980s, however, were the amalgamations of small hospitals (to exploit economies of scale, especially resulting from high-cost technological innovations in hospital care). It was not until the early 1980s that significant organisational reforms began to be successfully implemented.

The first major organisational reforms involved the creation of 14 Area Health Boards (AHBs), designed to strengthen decision-making by making AHBs responsible for planning all health services for their geographically based populations, and for delivering hospital, hospitalrelated, as well as public health services. AHBs were expected to work with primary health care service providers to plan services, but the funding for those services remained separate, managed by the Department of Health. AHBs were funded on a weighted-capitation basis (to encourage cost-consciousness).

While AHBs were being established during the 1980s, the New Zealand economy underwent radical reform. Drawing on free market economics thinking, the fourth labour (left-leaning) government (1984-1990) introduced major policies to liberalise the economy; inter alia, deregulating the financial system; reducing government assistance to key sectors, e.g. farming; removing or reducing trade protections; and selling key government-owned organisations or turning them into more business-oriented state-owned enterprises (SOEs) with an emphasis on reducing costs and ensuring profitability [15].

With major economic reforms occurring during the 1980s, it was inevitable that the New Zealand health sector would eventually come under similar scrutiny. In 1986, a Health Benefits Review was undertaken, led by academic economist Claudia Scott, sociologist/health policy specialist Geoff Fougère, and GP John Marwick.

The Review examined a wide range of issues relating to the performance of the New Zealand health system. In particular, it examined issues relating to the demand for health care-critiquing the selective nature of primary health care subsidies available in New Zealand, especially in primary health care; the low level at which some subsidies were set, leading to significant barriers to access to care from user charges and contributing to inequalities in health; and the impact of the benefits in influencing who provides care, e.g. limited use of nurses in primary health care given that the subsidy was paid for GP visits. The Review also examined issues relating to the supply of health care, noting that the rapid growth in hospital expenditure in recent years was concerning, and the growing evidence that primary health care investment might be a better use of resources. It also noted issues relating to market equilibrium, in particular raising concerns over the long waiting times for elective services in main centres, which in turn raised concerns over equity of access (evaluation at the whole system level) with those able to pay for themselves or through private health insurance having much better access to such care [9].

The Review compared and contrasted alternative approaches to organising relationships between purchasers and providers of health-care services, and the incentives each approach offered. It recommended the state retain its dominant position as funder of health services in New Zealand, but move to a mix of state and private provision 
and a greater use of contracts with providers. It also suggested reviewing user charges and the respective levels of subsidies paid for different services in primary health care (to reduce barriers to access to more cost-effective primary health care services) [9].

With the government of the day increasingly concerned with poorly managed public hospitals and growing waiting lists [16], it set up a second independent review. The Hospital and Related Services Taskforce was chaired by a prominent businessman and advocate of market-oriented reforms, Alan Gibbs [16]. The resulting 'unshackling the hospitals' Report noted similar issues to those raised in the Health Benefits Review, and went on to argue that significant efficiency gains could be made throughout the hospital sector, were the level of efficiency attained by certain services be achieved throughout New Zealand. The Report also argued that many of the incentives faced by New Zealand hospitals were inappropriate-most particularly that the incentives on AHBs were to support their own services as opposed to ensuring the most cost-effective provider delivered care.

This Report drew particularly on theories of managed competition [17]—i.e. economic thinking about how best to harness markets in health care, given the economic characteristics of health services, such as adverse selection, moral hazard, information asymmetries, and imperfect markets [18]. The report recommended the introduction of a purchaser-provider split, through the establishment of six locally-elected Regional Health Authorities acting as purchasers representing consumers. The Regional Health Authorities would buy services from both publicly and privately owned providers, with providers being paid for the value of the services they provided and hence making 'massive efficiency gains' [10].

\subsection{Re-Organising the Health System-the 1990s}

Although neither of these reviews resulted in significant changes to health policy in New Zealand at the time, they did significantly colour later thinking. In late 1990, the newly elected National Party-led government established a Health Services Taskforce to again review the New Zealand health system. The Taskforce was led by an economist, Dr Rod Carr. Drawing on the findings from the earlier reviews, the Taskforce recommended: the introduction of a purchaser-provider split, to focus health sector organisations' work; amalgamation of all health and disability budgets, to enable more cost-effective decision making; establishment of four geographically-based, governmentowned purchasing authorities known as Regional Health Authorities (RHAs), to systematically plan and purchase services; establishment of 23 government-owned Crown Health Enterprises (CHEs), building on the SOE model, to deliver hospital and hospital-related services, on contract to the purchasing authorities; the use of contracts for primary health care, community, and disability support services, to govern service delivery; the use of competition between providers, to encourage cost-effectiveness and responsiveness to consumers; and the development of a 'core' of services that should be funded, to set priorities [12].

The reforms were very unpopular-with a central government agency later noting that there was 'rejection of the "profit-driven" model for health and the jargon of management and economics rather than health' [19]. Implementation of the reforms was extremely expensiveestimated at between $\$ \mathrm{NZ} 85 \mathrm{~m}$ and $\$ \mathrm{NZ348m}$, and in some cases up to $\$ N Z 800 m$ [16]. The reforms also generally failed to live up to their expectations [19]. Most importantly, the major savings envisaged did not eventuate: public hospitals were found to be largely underfunded for the services they delivered and further changes in service delivery models proved difficult to achieve, particularly in the prevailing political environment $[6,19]$. With no savings made, the promised reductions in waiting times similarly did not occur, with waiting lists rising significantly [20].

In primary health care, however, the reforms did have some positive outcomes. New networks developed to represent GPs in negotiations with RHAs and hence to offset the monopsony power of RHAs, but these also enabled new ways of contracting to encourage increases in efficiency, improvements in quality of care, and more services delivered across general practices; as a result, RHAs did make savings in primary health care expenditures. In addition, with resources no longer automatically allocated to particular providers and the ability of the RHAs to allocate resources as they saw fit, it allowed many new Māori- and Pacific-led providers to be established and funded, to better deliver services to these higher-need populations [21, 22].

The reforms may, however, have also been detrimental to health outcomes, with too much emphasis on costs and insufficient emphasis on quality of care at times [23, 24].

In 1996, it was recommended that (1) the four RHAs be amalgamated into a single, national purchasing authority to reduce overall transaction costs and improve national consistency and (2) that CHEs should become Hospital and Health Services (HHSs), with their profit motive removed but with continued expectations that they would be expected to cover their costs [25]. Following a further period of reorganisation [16], by late 1998, the single Health Funding Authority (HFA) was established and was beginning its work. 


\subsection{Re-Organising the Health System—the 2000s}

The purchaser-provider split model as a whole was overturned with the return to power of a Labour-led government in late 1999. In 2001, New Zealand reverted, in part, to the model developed during the 1980s, with 21 (now 20) geographically based District Health Boards (DHBs) established by a new Labour-led coalition government. The function of DHBs is to plan services for their districts, and-to reduce the uncertainties for hospitals over contracting and to reduce transaction costs- to deliver hospital and hospital-related services. Aspects of the purchaserprovider split arrangements continue, however, with primary health care and community providers formally contracted by DHBs for the services they provide. DHBs now hold the budgets for primary health care services, although many of the arrangements for funding and delivery are determined by the Ministry of Health.

Assessments of these reforms have shown that the local focus of DHBs is generally supported, but concerns have been raised that DHBs may prioritise their own service delivery as opposed to services delivered by privately owned providers, potentially leading to an over-emphasis on hospital services, fewer cost-effective service delivery arrangements, and limited pressure to improve hospital productivity [26].

In 2008, a new National Party-led coalition government was formed; it established yet a further review of the health system through a Ministerial Review Group. The groupchaired by former Secretary of the Treasury, Dr Murray Horn-again focused on issues relating to decision making, as well as ways to reduce administration costs within the health system. The Group recommended a new National Health Board (NHB) be established to take over the function of planning and funding of national health services, as well as the monitoring of DHBs. The Review Group argued that the separation of Ministry and NHB functions would "provide clearer separation between the development of health policy and its implementation ... and much clearer roles and accountabilities" [14] p. 33 . This may have effectively re-established the HFA, which was dis-established in 2000; but in implementing the recommendations of the Group, a later decision was taken to leave the NHB within the Ministry of Health, to encourage greater linkages between policy and purchasing decisions.

\section{New Zealand Health Economics and Priority Setting}

A second major area where health economics has played a considerable part in health policy in New Zealand is in relation to priority setting. The major attention played to explicit and rigorous priority setting, and the strong use of economic tools, began during the reforms of the 1990s. The emphasis remains today in three key areas: pharmaceuticals expenditure; more general prioritisation including health technology assessment; and elective services.

\subsection{PHARMAC}

With pharmaceutical expenditure rising at up to $15 \%$ per annum during the 1980s, faster than other health spending [27], it was recognised that New Zealand needed a new approach to pharmaceutical spending management. In 1993, the four RHAs became responsible for the pharmaceuticals budget. Faced with an overall budget cap in which they were expected to work, the RHAs jointly established a Pharmaceutical Management Agency (PHARMAC) to better manage pharmaceutical expenditure. PHARMAC has gone on to become the most enduring of the organisations established during the 1990s reforms [28] and highly successful at restraining medicines expenditure in New Zealand, expanding the range and volume of medicines able to be accessed by New Zealanders at far lower levels of expenditure than would otherwise occur [29]. Key features of its work include [30]:

- Determining a medicine's priority using cost-effectiveness analyses alongside other criteria such as health needs; the health needs of Māori and Pacific populations; availability of existing treatment options; clinical benefits and risks; budgetary impact, etc.

- A therapeutic group approach, which funds equivalent medicines at the lowest price, forcing pharmaceutical companies to accept the PHARMAC price as full payment or charge individual patients an additional fee.

- A capped budget.

- Negotiations between PHARMAC and pharmaceutical companies to keep prices low.

- Tenders for off-patent medicines, involving a sole supply arrangement for the whole of New Zealand (e.g. amoxicillin [31], some antipsychotic medicines [32]).

Since 2002, PHARMAC estimates that it has saved DHBs \$NZ3.8 billion $^{1,2}$ against forecast expenditures through its work [34]. PHARMAC has survived numerous changes of government and has had its role expanded to include hospital medicines and, most recently, devices. Critics argue that PHARMAC means New Zealanders do not have access to the same range of medicines as other countries, leads to uneconomic prices, poses risks to health,

\footnotetext{
1 At October 2014, equivalent to \$US2.89 billion; £1.81 billion; and $€ 2.3$ billion (where a billion is one thousand million i.e. $1,000,000,000)$.

2 In 2013, pharmaceutical expenditure totalled \$NZ 783.6 million [33].
} 
and that it is slow to make decisions, lacks transparency, and at times places supply at risk through sole-supplier arrangements [29]. But on only two significant occasions have New Zealand governments 'overturned' PHARMAC decisions, where PHARMAC had argued there was a lack of evidence about the cost-effectiveness of the medicines involved. In both cases, PHARMAC decisions were 'overturned' as a result of election promises. Thus in 1999, the Labour-led government enabled the funding of interferon beta for multiple sclerosis; while in 2008, the National Party-led government allowed funding to support the 12-month course of breast cancer medicine trastuzumab for HER2-positive breast cancer[29].

\subsection{Explicit Priority Setting Beyond Medicines}

As noted earlier, one of the key recommendations in the 1991 reform proposals was for an explicit 'core' of services to be defined, clarifying the services New Zealanders would have access to through government funding, and hence clarifying the range of services New Zealanders would have to fund themselves. An independent advisor to the government-the Core Services Committee (CSC) was established in 1992 to take on this role.

The CSC considered a number of alternatives to setting priorities within the New Zealand health system, but in the end focused on identifying key principles for determining priorities: what are the benefits? Is it value for money? Is it fair; and is it consistent with the community's values and priorities? [35, 36]. The CSC consulted widely on these principles and these-and similar principles-continue to influence thinking on priority setting today. The CSC's early work resulted in an increased focus in New Zealand on explicit priority setting in two key areas.

First, was the development of practice guidelines; these guidelines assessed evidence, considered the CSC's priority setting principles, and produced a consensus on when services might be considered to be of benefit and to offer good value for money for different service users with particular conditions. This work continued through the notfor-profit New Zealand Guidelines Group, with funding provided by the government (and other organisations) [37].

Second, the CSC promoted the need for improved priority setting and management processes for elective services (see below). This work eventually flowed through the Ministry of Health's Electives Programme [38].

Having spun off its work on guidelines and elective services, the CSC itself then focused on a series of projects on improving health services [39], becoming known as the National Health Committee (NHC) in 1998.

In 2011, the National Health Committee's work was again changed towards providing advice on value for money and prioritisation (other than for pharmaceuticals and devices, which remain the responsibility of PHARMAC) [39]. The NHC works with 11 decision-making criteria, including clinical safety and effectiveness, health and independence gain, feasibility, cost-effectiveness, etc. [39]. It remains too early to examine the work of the NHC in depth at this point in time.

\subsection{Elective Services}

In New Zealand, elective services are operations such as hip and knee joint replacements and cataract surgery, for conditions which are not immediately life threatening. With public funding for hospital services capped by central government, elective services are one area where hospitals in New Zealand have always formally rationed care, with waiting lists used to 'park' patients who cannot be treated immediately. Long waiting times and lists for elective services have been a key concern in the New Zealand health system since the 1960s [20], with patients viewing the lists as a key indicator of an under-funded health system and governments focused on waiting times and lists as a result of the significant attention paid to them.

As one of its first tasks examining issues relating to priority setting in the New Zealand health system, the CSC commissioned a report into the management of elective services in 1993. The resulting report suggested waiting lists for such services were poorly managed, that some service users waited far too long for care, with some never being sure if they would ever be treated through the publicly funded health system [40]. The report suggested a new approach. This drew on economic ideas relating to value for money: it would focus on assessing patients using agreed criteria, based on need (ability to benefit), and a guarantee of surgery for those who met the criteria [40].

From the mid-1990s onwards, New Zealand governments have developed a series of new policies and processes to better manage waiting lists. The way in which the system now operates involves:

- Patients referred for elective surgery must be told within 10 days if they will be formally assessed.

- DHBs then have 5 months to undertake an assessment, using mostly clinical criteria but also including some social criteria (relating to independence and carer responsibilities).

- Patients scoring more than the threshold number of points set by each DHB are then to be booked and receive their surgery within 5 months of the assessment; other patients are returned to their GPs for any care they might need [20].

Note that the elective services system has a strong circularity to it - the points required by service users are developed with reference to the ability of each DHB to 
treat service users within the time frames set by the government of the day. Currently, the government is moving to have 4-month targets for assessments and treatments.

As noted above, the system is designed to have a key focus on assessing need, originally defined as 'ability to benefit' (from surgery). The system relied, then, on clinicians accepting the need for patients to be prioritised, and devising criteria that could then be used to assess patients. The system was, in practice, extremely difficult to develop and then to implement across New Zealand's DHBs, with a wide range of concerns expressed about the ethics of prioritising patients, the criteria to be used, and the extent to which the chosen criteria would indeed allow the system to focus treatments on those with the most to gain [20]. Furthermore, the process became difficult to implement without additional funding. Thus, at times, some New Zealanders on waiting lists were told they were being dropped from the lists, with the process becoming highly politicised [20].

In spite of difficulties over many years, the electives priority setting system remains in place today. From the government's perspective, the system has successfully removed the focus of the public on waiting lists and times, and provides an important means by which the government holds DHBs to account for a key aspect of performance. The government is currently paying attention to further reducing the waiting times for those accepted into the system. From an economics perspective, however, the system continues to be criticised. It has eliminated poorly managed waiting lists but no information is available on those returned back to their GPs for care, opening the government up to criticism that it is simply hiding 'waiting lists' to achieve its waiting times goals, and reducing the potential for more thoughtful consideration of whether it is better value for money to treat those accepted for surgery more quickly, or offer those currently not being treated access to surgery. From an equity perspective, the system also does not provide the national consistency that was originally desired-the tools used to score patients differ around the country, actual scoring processes differ, and the points needed to receive treatment also differ according to where a patient lives, and may change over time [20]. In addition, overall, there is no clear assessment of whether the criteria being used do focus on aspects of ability to benefit and whether the electives system leads to overall high levels of value for money by successfully selecting those patients with the most to gain from treatment.

\section{Conclusions}

In this paper, I have discussed key examples of how health economists and health economics have had a significant influence in health policy in New Zealand since the mid1980s. Using Williams's [2] framework, I have emphasised how the numerous reviews of the organisation of the health system,-i.e. evaluations at the whole system level-have persistently used economists and economics frameworks to analyse the performance of the health system. Economic principles have also underpinned many reforms_-including the use of capped budgets to provide incentives and restrain expenditure; a focus on establishing organisations that can independently make resource allocation decisions; and the use of contracts and competition to guide resource allocation and service delivery. I have also shown how, in New Zealand, attention to Williams's market equilibrium area of focus-around waiting lists and non-price rationing - usecost-effectiveness principles and analyses to support decision making.

The 1990s reforms demonstrate, however, how an emphasis on internationally developed health economics theories to design a health system can lead to major problems, especially where local context, values, costs of change, and political factors are not adequately considered. These reforms cost New Zealand significant sums of money, distracted the sector's attention away from key issues, and have been shown to be detrimental to health outcomes. The reforms have left a legacy of a major aversion to significant organisational reform in the New Zealand health sector that is still evident today.

Even though the 1990s reforms generally failed to achieve the key objective of improving efficiency and generating savings, review after review continues to return to the idea of separating out the role of decisionmaking/ purchasing from that of providing services, with concerns that today's DHBs still have an incentive to prioritise their own hospital services to the detriment of achieving improved primary health and community care services and hence improved overall cost-effectiveness. Some still rue the more recent decision to leave the NHB within the Ministry of Health, suggesting a stand-alone purchasing authority offers the best chance of improved decisionmaking and allocation of resources to the most costeffective service providers.

The 1990s reforms, however, also left positive legacies-the development of the highly successful PHARMAC, the emphasis on explicit priority setting that still exists in the electives system today, the establishment of new networks of primary health care providers that now underpins primary health care policy, and the continued existence of Māori- and Pacific-led providers working to improve the health of their populations.

Beyond medicines and electives, however, concerns remain about how resources are allocated within the New Zealand health system. A number of attempts have been made by various organisations at various points in time, to 
extend a more rigorous priority setting approach to the vast range of health services delivered within the health care system on a day-to-day basis. The HFA developed a PHARMAC-like approach during the late 1990s [41-44], but this was shelved when the HFA was abolished in 2000. The Ministry of Health used a principles-based approach to guide DHB priority setting [45], and although there were some early indications of clear decisionmaking, in particular where there was new funding [46], little is known about how DHBs now go about determining their own priorities. At a national level, the NHC in 2005 [47] noted how under-developed mechanisms were for assessing relative cost-effectiveness for new and costly interventions, especially those where it might be felt only one or several DHBs might most efficiently invest in a new technology. However, national arrangements put in place in the mid-tolate 2000s to manage this issue are generally felt to have failed, in part due to the lack of clear linkage between such decisions and funding, given devolution of many funding decisions to DHBs [14]. Most recently, the NHC has been reconstituted to improve this situation. How successful it will be remains to be seen.

There remain other key gaps where economists might contribute more to improve the performance of the health sector. In terms of Williams's framework, there is a significant need for more economics research and commentary on issues relating to:

- what is health and what is its value? little research having been done on this topic since the late 1990s [48],

- the demand for health care, including health seeking behaviour,

- the supply of health care, in particular an understanding of the drivers of hospital productivity,

- micro-economic evaluation at treatment level, i.e. better information and analyses to support cost-effectiveness and prioritisation decisions beyond medicines, especially New Zealand-specific information; and,

- at the system level, analyses of variations in use of services and stronger incentives to manage these; an understanding of the impact of recent primary health care reforms and alternative models of care, and their impact on health, hospital admissions, and overall expenditures; and the outcomes achieved from the range of services delivered-New Zealand has no focus on patient-reported outcomes as is developing in other countries [49], but we cannot effectively assess the relative value for money generated by different services or service providers without such a focus.

Conflicts of interest None.
Funding for the paper None.

\section{References}

1. Black J. Oxford dictionary of economics. Oxford; Oxford University Press; 1997.

2. Williams A. Health economics: the cheerful face of a dismal science. In: Williams A, editor. Health and Economics. London: Macmillan; 1987.

3. Statistics New Zealand. Population clock. Wellington; Statistics New Zealand; 2014. http://www.stats.govt.nz/tools_and_services/ population_clock.aspx. Accessed 8 Aug 2014.

4. Statistics New Zealand. New Zealand in profile 2014, vol. 8. Wellington: Statistics New Zealand; 2014.

5. Ministry of Health. Health expenditure trends in New Zealand 2000-2010. Wellington: Ministry of Health; 2012.

6. Cumming J, McDonald J, Barr C, Martin G, Gerring Z, Daubé J. New Zealand: health system review. Geneva: World Health Organization; 2014.

7. New Zealand Government. A review of hospital and related services in New Zealand. Wellington: Department of Health; 1969.

8. New Zealand Government. A health service for New Zealand. Wellington: Government Printer; 1974.

9. Health Benefits Review. Choices for health care: report of the health benefits review. Wellington: Health Benefits Review; 1986.

10. Hospital and Related Services Taskforce. Unshackling the hospitals. Wellington: Hospital and Related Services Taskforce; 1988.

11. Hay I. The caring commodity: the provision of health care in New Zealand. Auckland: Oxford University Press; 1989.

12. Upton S. Your health and the public health: a statement of government health policy. Wellington: Minister of Health; 1991.

13. National Health Committee. Improving health for New Zealanders by Investing in primary health care. Wellington: National Health Committee; 2000.

14. Ministerial Review Group. Meeting the challenge: enhancing sustainability and the patient and consumer experience within the current legislative framework for health and disability services in New Zealand: report of the Ministerial Review Group. Wellington: Ministerial Review Group; 2009.

15. Holland M, Boston J, editors. The fourth labour government. Auckland: Oxford University Press; 1990.

16. Gauld R. Revolving doors: New Zealand's health reforms-the continuing saga. 2nd edition. Wellington: Institute of Policy Studies and the Health Services Research Centre; 2009.

17. Enthoven A. Managed competition of alternative delivery systems. J Health Politics Policy Law. 1988;13(2):305-21.

18. Mooney G. Economics, medicine and health care. Brighton: Wheatsheaf; 1986.

19. Crown Company Monitoring Advisory Unit. Crown health enterprises: briefing to the incoming minister. Wellington: Crown Company Monitoring Advisory Unit; 1996.

20. Cumming J. New Zealand. In: Siciliani L, Borowitz M, Moran V, editors. Waiting time policies in the health sector: what works? Paris: Organisation for Economic Co-operation and Development; 2013. p. 201-20.

21. Ashton T. The purchaser-provider split in New Zealand: the story so far. Aust Health Rev. 1995;18(4):43-60.

22. Cumming J, Salmond G. Reforming New Zealand health care. In: Ranade W, editor. Markets and health care: a comparative analysis. New York: Addison Wesley Longman; 1998. 
23. Health and Disability Commissioner. Canterbury health Ltd. Auckland: Health and Disability Commissioner; 1998.

24. Carryer J, Diers D, Wilson D. Effects of health policy reforms on nursing resources and patient outcomes in New Zealand. Policy Politics Nursing Pract. 2010;11(4):275-85.

25. Agreement Coalition. Coalition agreement between New Zealand First and the New Zealand National Party. Wellington: Coalition Government; 1996.

26. Mays N, Cumming J, Tenbensel T. Health reforms 2001 research: overview report. Health reforms 2001 research project: report No. 1. Wellington: Health Services Research Centre; 2007.

27. Ministry of Health. Health expenditure trends in New Zealand 1990-200. Wellington: Ministry of Health; 2002.

28. Ragupathy R, Tordoff J, Norris P, Reith D. Key Informants' Perceptions Of How Pharmac Operates In New Zealand. Int $\mathbf{J}$ Technol Assess Health Care. 2012;28(04):367-73. doi:10.1017/ S0266462312000566.

29. Cumming J, Mays N, Daubé J. How New Zealand has contained expenditure on drugs. Br Med J. 2010;340(5 June):1224-7.

30. Pharmaceutical Management Agency (PHARMAC). Operating policies and procedures of the Pharmaceutical Management Agency (PHARMAC) 3rd ed. Wellington: PHARMAC; 2006.

31. Pharmaceutical Management Agency (PHARMAC). May 2014 early tender notification. PHARMAC, Wellington. 2014. http:// www.pharmac.health.nz/news/notification-2014-05-19-tender/. Accessed 24 Dec 2014.

32. Pharmaceutical Management Agency (PHARMAC). Antipsychotic medicines. PHARMAC, Wellington. 2014. http:// www.pharmac.health.nz/medicines/my-medicine-has-changed/ antipsychotic-medicines/. Accessed 24 Dec 2014.

33. Pharmaceutical Management Agency (PHARMAC). Annual review. Wellington: Pharmac; 2013.

34. Pharmaceutical Management Agency (PHARMAC). Annual report. Wellington: Pharmac; 2013.

35. National Advisory Committee on Core Health and Disability Services. The best of health: deciding on the health services we value most. Wellington: National Advisory Committee on Core Health and Disability Services; 1992.

36. National Advisory Committee on Core Health and Disability Support Services. The best of health 2: how we decide on the health and disability support services we value most. wellington: National Advisory Committee on CORE Health and Disability Support Services; 1993.
37. Ministry of Health. New Zealand guidelines group. Wellington: Ministry of Health. 2014. http://www.health.govt.nz/aboutministry/ministry-health-websites/new-zealand-guidelines-group. Accessed 8 Aug 2014.

38. Ministry of Health. Elective services. Wellington: Ministry of Health. 2014. http://www.health.govt.nz/our-work/hospitals-andspecialist-care/elective-services? $\operatorname{mega}=\mathrm{Our} \% 20$ work $\&$ title $=$ Elective\%20services.

39. National Health Committee. Wellington: National Health Committee. 2014. http://nhc.health.govt.nz/home. Accessed 8 Aug 2014.

40. Fraser G, Alley P, Morris R. Waiting lists and waiting times: their nature and management. Wellington: National Advisory Committee on Core Health and Disability Support Services; 1993.

41. Health Funding Authority. How shall we prioritise health and disability services?. 14th ed. Wellington: Health Funding Authority; 1998.

42. Health Funding Authority. Prioritisation methodology and process. Wellington: Health Funding Authority; 1998.

43. Ashton T, Cumming J, Devlin N. Prioritising health and disability support services: principles, processes and problems. Wellington: National Advisory Committee on Health and Disability; 1999.

44. Ashton T, Cumming J, Devlin N. Priority-setting in New Zealand: translating principles into practice. J Health Services Res Policy. 2000;5(3):170-5.

45. Ministry of Health, District Health Boards New Zealand. The best use of available resources: an approach to prioritisation. Wellington: Ministry of Health; 2005.

46. Coster G, Mays N, Scott C, Cumming J. The impact of health needs assessment and prioritisation of District Health Board planning in New Zealand. Int J Health Plan Manag. 2009;24(4): 276-89.

47. National Advisory Committee on Health and Disability. Decision-making about new health interventions: a report to the minister of health. Wellington: National Advisory Committee on Health and Disability; 2005.

48. Devlin N, Hansen P, Kind P, Williams AH. The health state preferences and logical inconsistencies of New Zealanders: a tale of two tariffs. York: Centre for Health Economics, University of Otago; 2000.

49. Black N. Patient reported outcome measures could help transform healthcare. BMJ 2013;346:f167. doi:10.1136/bmj.f167 